\title{
Evidence for Failure of V(D)J Recombination in Bone Marrow Pre-B cells from X-linked Agammaglobulinemia
}

\author{
Jerrold Schwaber \\ Center for Blood Research and Department of Pathology, Harvard Medical School, Boston, Massachusetts 02115; \\ and Department of Pathology, Hahnemann University, Philadelphia, Pennsylvania 19102
}

\begin{abstract}
X-linked agammaglobulinemia (XLA) results from a failure of B lymphoid development. We have previously examined pre-B cell hybrids from three patients with XLA and found them to be limited to production of a novel germ line transcript of the $\mathrm{Ig} \mathrm{H}$ chain locus composed of a leader sequence (LS) spliced to the constant region of $\mu$ chain $(C \mu)$ as mRNA and polypeptide. These transcripts result from transcriptional activation of the germ line heavy chain locus from an LS exon upstream of the embryonic $J_{H}$ locus. Germ line LS-C $\mu$ transcripts are produced by pre-B cells from normal bone marrow and fetal liver, indicating that they are products of normal pre-B cell development, as part of the process of transcriptional activation to provide access for the recombinase. Bone marrow from three patients with XLA has been examined directly by polymerase chain reaction amplification to determine whether the exclusive production of $\mathrm{LS}-\mathrm{C} \mu$ by XLA pre-B cell hybrids is representative of XLA pre-B cells. I report that $\mathrm{LS}-\mathrm{C} \mu$ is the predominant $\mathrm{Ig}$ molecule produced by XLA pre-B cells, with limited production of the $D \mu$ product of $D J_{H}$ intermediate stage of $V(D) J$ recombination. Mature $V_{H} D J_{H}$ recombinations were not detected with a variety of primers that amplify $V_{H}$ sequences. I conclude that XLA is associated with a limitation in $V(D) J$ recombination that may cause the failure of pre-B cell development. (J. Clin. Invest. 1992. 89:2053-2059.) Key words: immunoglobulin • B lymphocytes • transcriptional activation • antibody deficiency • polymerase chain reaction
\end{abstract}

\section{Introduction}

$\mathrm{X}$-linked agammaglobulinemia (XLA) ${ }^{1}$ is a congenital antibody deficiency disease linked to Xq2 $(1,2)$. The major phenotype of XLA is associated with arrest in B lymphoid develop-

Address reprint requests to Jerrold Schwaber, Pathology MS 435, Hahnemann University, Broad and Vine, Philadelphia, PA 19102.

Received for publication 8 November 1991 and in revised form 17 January 1992.

1. Abbreviations used in this paper: $\mathrm{C} \mu$, constant region of $\mu$ chain; $\mathrm{D}$, diversity; J, joining; LS, leader sequence; PCR, polymerase chain reaction; PGK, phosphoglycerate kinase; V, variable; XLA, X-linked agammaglobulinemia.

J. Clin. Invest.

(c) The American Society for Clinical Investigation, Inc.

0021-9738/92/06/2053/07 \$2.00

Volume 89, June 1992, 2053-2059 ment at the stage of pre-B cells (3). This arrest is generally accepted to be causative of the disease. Rare B lymphocytes are found in peripheral blood of some patients, constituting $<1 \%$ of the B cell population of a normal individual (4). The failure of B lymphoid development is subject to X chromosome inactivation in carriers, with consequent clonal failure of development of B lymphocytes from precursors in which the XLA bearing chromosome is active $(5,6)$. Normal development of $B$ lymphocytes in which the disease-bearing $\mathrm{X}$ chromosome is inactivated indicates that the disease is recessive and intrinsic to the B lymphoid precursors.

The primary event in pre-B cell development is recombination of immunoglobulin variable diversity joining $(\mathrm{V}(\mathrm{D}) \mathrm{J})$ gene elements to generate a functional variable region (7). Variable regions are assembled by selection and recombination from the sets of $\mathrm{V}, \mathrm{D}$, and $\mathrm{J}$ gene elements in an ordered sequence $(8,9)$. First a $D$ gene element is recombined with a $J_{H}$ gene element, and then a $V_{H}$ is recombined with the $D_{H_{H}}$ intermediate (10). Formation of a mature $\mathrm{V}_{\mathrm{H}} \mathrm{DJ}_{\mathrm{H}} \mathrm{C} \mu$ is followed by light chain recombination. $\mathrm{V}(\mathrm{D}) \mathrm{J}$ recombination is catalyzed by a single recombinase that acts in the sequential steps of Ig recombination and in the recombination of $\mathrm{T}$ cell antigen receptors (11). The recombinase is proposed to be directed in its cell lineage specificity and in its sequential steps of recombination by control of its access (12). Transcriptional activation of the recombining gene elements is associated with access for the recombinase. Transcription of unrearranged $V_{H}$ gene elements and $\mathrm{DJ}_{\mathrm{H}}$ intermediate structures occurs in close correlation with $\mathrm{V}_{\mathbf{H}}$ to $\mathrm{DJ}_{\mathrm{H}}$ recombination $(13,14)$. Germ line transcriptional activation of the $J_{H}$ locus precedes $D$ to $J_{H}$ recombination $(14,15)$, and activation of the $J_{K}$ locus precedes $V_{\kappa}$ to $J_{K}$ recombination (16). Similar transcriptional activation occurs in recombination of the elements of the $T$ cell antigen receptor (17).

We have previously proposed that the failure of pre-B cell development in XLA results from a primary failure of $\mathrm{Ig} V(D) J$ recombination (18). This proposal resulted from the exclusive production of germ line transcripts of the heavy chain locus by pre-B cell hybrids from XLA bone marrow. Germ line transcripts, composed of a leader sequence (LS) spliced to the constant region of $\mu$ chain $(C \mu)$, were produced by a limited number of pre-B cell hybrids derived from normal fetal liver, indicating that $\mathrm{LS}-\mathrm{C} \mu$ was a product of normal pre-B cell development. LS-C $\mu$ is the product of an LS exon that is 14-16 $\mathrm{kb}$ upstream of the $\mathrm{J}_{\mathrm{H}}$ locus (15). Transcription from the LS exon provides transcriptional activation of the $J_{H}$ locus.

I have now used the polymerase chain reaction (PCR) to determine whether the exclusive production of germ line transcripts by XLA pre-B cell hybrids is representative of XLA 
bone marrow pre-B cells. I find that LS-C $\mu$ is a product of normal bone marrow, and is the predominant product of XLA bone marrow. Some $\mathrm{D} \mu$ transcripts from the $\mathrm{DJ}_{\mathrm{H}}$ intermediate step of recombination are present in XLA bone marrow. Mature $\mathrm{V}_{\mathrm{H}} \mathrm{DJ}_{\mathrm{H}} \mathrm{C} \mu$ products were not identified in bone marrow from three XLA patients, using a variety of $5^{\prime}$ primers for amplification. These results indicate that $\mathrm{V}(\mathrm{D}) \mathrm{J}$ recombination is a rate-limiting step in XLA bone marrow pre-B cells, associated with the failure of pre-B cell development.

\section{Methods}

Samples of bone marrow were obtained by biopsy of iliac crest. Bone marrow was aspirated into preservative-free heparin. Informed consent was obtained from each individual biopsied, following procedures approved by the Committee on Human Subjects at Children's Hospital of Boston. Mononuclear cells were separated by buoyant density centrifugation on Ficoll-paque (Pharmacia Fine Chemicals, Piscataway, NJ), and adherent cells were removed by incubation in plastic (petri shaped) culture dishes overnight at $37^{\circ}$. Resulting cells were counted, pelleted by centrifugation, the supernatant removed, and stored as cell pellets at $-80^{\circ}$. Normal fetal liver RNA was kindly provided by Dr. Eric Hoffman (University of Pittsburgh, PA).

RNA was extracted from cell pellets by lysis in guanidine- $\mathrm{HCl}$ as described by Chirgwin et al. (19), followed by differential ethanol precipitation, and phenol and chloroform extraction. cDNA was synthesized with cloned Moloney murine leukemia virus reverse transcriptase (Bethesda Research Laboratories, Gaithersburg, MD) using random hexamer primers. $5 \mu \mathrm{l}$ of reaction was removed, mixed with $10 \mu \mathrm{Ci}$ of ${ }^{32} \mathrm{P}$ dCTP, and incubated in parallel. Radioactivity incorporated was used to determine the amount of cDNA synthesized.

Genomic DNA for Southern blotting was digested with HindIII to completion, electrophoresed, transferred to Gene Screen Plus (New England Nuclear, Boston, MA) and probed with the 2-kb Sau3AI fragment of the human genomic $\mathbf{J}_{\mathbf{H}}$ locus clone described by Ravetch et al. (20).

PCR amplification was performed with reagents and Taq 1 polymerase from Perkin-Elmer Cetus (Norwalk, CT) with a thermal cycler (Perkin-Elmer Cetus). Standard conditions used $94^{\circ}$ (denaturation) for 1 min, $70^{\circ}$ (annealing) for $1 \mathrm{~min}, 72^{\circ}$ (amplification) for $2.5 \mathrm{~min}$ for 30 cycles. When a secondary amplification was done, $1 \mu \mathrm{l}$ of primary product was diluted 1:20, and $1 \mu \mathrm{l}$ used for amplification. Alternatively, the relevant region was excised from a low melt agarose gel (TAE

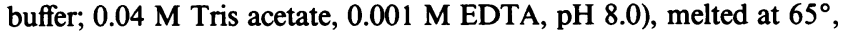

extracted with phenol and then chloroform, precipitated with ethanol, and resuspended in two times the starting volume. Agarose gel purification was occasionally necessary to prevent formation of smearing, likely the result of production of primer multimers.

Primers used for amplification were:

LSP 5'AGACTCTCCTGTGCAGCCTCTGGATTCACCTTCAGT $3^{\prime}$ $\mathrm{V}_{\mathrm{H}} 1$ 5'TCAGTGAAGGTTTCCTGCAAGGCATCTGGATACACC $3^{\prime}$ $\mathrm{V}_{\mathrm{H}} 2$ 5'AAGCCTTCACAGACCCTGTCCCTCACCTGCACTGTCTCT $3^{\prime}$

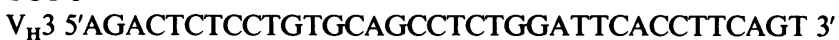
$\mathrm{V}_{\mathrm{H}} 4$ 5'GCTGTCTCTGGTTACTCCATCAGCAGT $3^{\prime}$

$\mathrm{V}_{\mathrm{H}} 6$ 5'GTGTCCTGTCACAGGTACAGCTGCAGCAGTCA 3'

CMIII 5'TGCTGGACTTTGCACACCACGTGTTCGTCTGT 3' (-strand) 247 to 278 of $\mathrm{C} \mu$

CMI 5'AGTGATGGAGTCGGGAAGGAAGTCCTGT 3' (-strand) 93 to 121 of $\mathrm{C} \mu$

DXP 5'GGTTTGGGGTGAGGTCTGTGTCACTGTGGTAGG 3'

DLR 5'GGATTTTGTGGGGGCTTGTGTCACTGTGAGAAG 3'

DHQ52 5'CTGAGCTGAGAACCACTGTGCTAACT 3'

CM4R 5'CAACTTGGTGGACTTGTTCAGGAAGATGCT 3' (-strand) 700 to 730 of $\mathrm{C} \mu$

CM5F 5' AAGACGTGCCTCTTCCAGTGATTG 3' 299 to 323 of $\mathrm{C} \mu$.

The positions of these primers and their expected amplification products are shown in Fig. 1. The primer pairs all span introns, ensuring that amplification is from cDNA rather than genomic DNA. The D primers extended upstream of the coding region including the heptamer to prevent amplification of $D$ sequence from $V_{H} D J_{H}$ recombinants. Several controls were used to ensure specific amplification. Each reaction included a tube to which template cDNA was not added as a negative control. Comparable amplification reactions were prepared as a batch including all reagents except template, aliquoted into individual reaction tubes, and template cDNA was then added. That different samples of cDNA were equally able to be amplified was checked by comparing the yield of product of amplification with the housekeeping enzyme phosphoglycerate kinase (PGK). Amplification with the LSP primer required amplification with the Klenow fragment of DNA polymerase I, performed for two cycles with $30^{\circ}$ annealing for $1 \mathrm{~min}$, and $37^{\circ}$ amplification for $2 \mathrm{~min}$. This low temperature amplification was required with normal bone marrow and fetal liver, and the three XLA bone marrows, likely because of polymorphism in the leader sequence.

PCR amplification products were examined by ultraviolet light transillumination of ethidium bromide-stained agarose gels and by transferring the contents of the gel to membrane (nitrocellulose and Gene Screen Plus were used variably). Southern blots to nitrocellulose

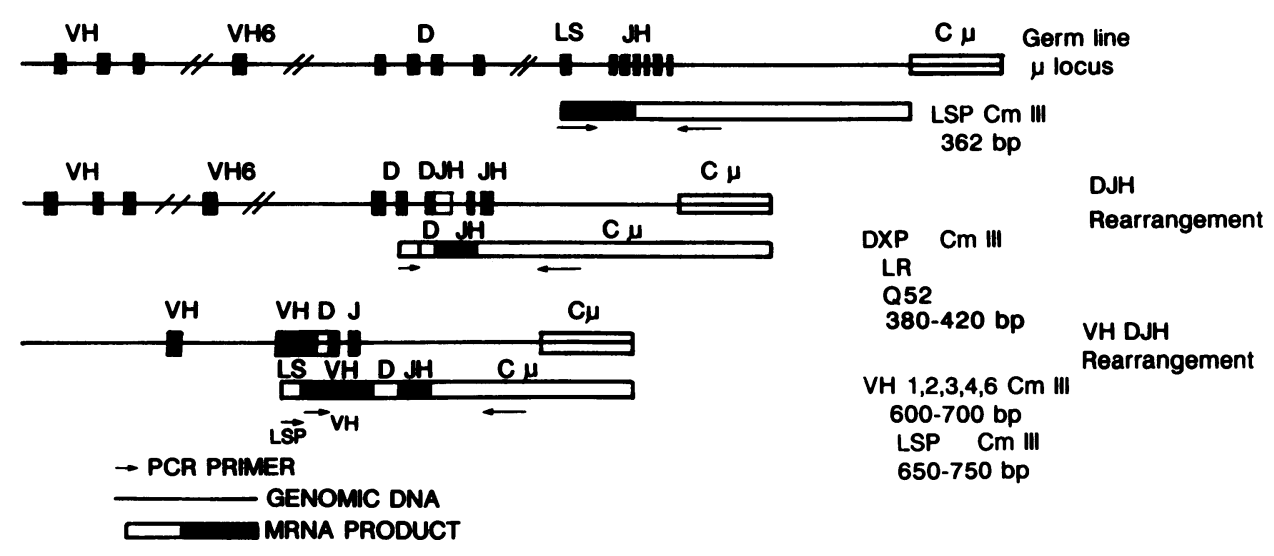

Figure 1. PCR primers and products. Diagram of the various PCR primers and expected amplification products used to evaluate $\mathrm{Ig} \mathrm{H}$ chain rearrangement and germ line transcription. The top line is a schematic map of the germ line $\mathrm{H}$ chain locus (not to scale), including the LS exon upstream of the $J_{H}$ locus. Subsequent lines show partial or fully rearranged alleles. Below each line is the processed mRNA (bar) from the genomic DNA (line) in expanded size. Arrows below the mRNA depict the positions of the primers. Sequences of the primers are given in Methods. The sizes of the expected products are given at the right side of the figure. 


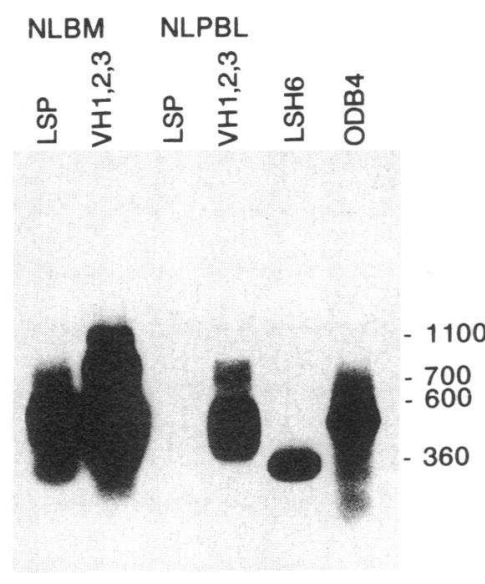

Figure 2. Control amplifications. Amplification assays of control cDNAs from normal tissues. (NLBM) Normal bone marrow amplified with the LSP or $\mathrm{V}_{\mathrm{H}} 1, \mathrm{~V}_{\mathrm{H}} 2$, and $\mathrm{V}_{\mathrm{H}} 3$ primers. (NLPBL) Normal peripheral blood lymphocytes amplified with the same primers. (LSH6) A pre-B cell hybrid derived from normal fetal liver, limited to production of LS-C $\mu$ germ line transcripts.

(ODB4) A normal B cell hybrid that produces mature $\mu$ chain that is an anti-DNA autoantibody (31).

were performed as described previously (15). The PCR blots were probed with the 1.6-kb C $\mu$ cDNA insert from the plasmid $\mathrm{p} \mu \mathrm{HM} 2$ (18).

Markers were either $\lambda$ DNA digested with HindIII or phiX174 digested with Hinfl.

\section{Results}

The primers used for these experiments, their positions on mature and precursor mRNAs (cDNAs), and the anticipated amplification products of these primers are shown in Fig. 1.

Control experiments. The expected product of LSP (leader sequence) and $\mathrm{C} \mu$ primers amplifying $\mathrm{LS}-\mathrm{C} \mu$ is $362 \mathrm{bp}$. Amplification of cDNA from the LS-C $\mu$ producing pre-B cell hybrid LSH6 yielded a single band migrating at 360 bp (Fig. 2). This PCR product has identical sequence to the $\mu \mathrm{b} 9 \mathrm{cDNA}$ clone isolated from the LSH6 hybrid. Because of the near identity of the LS to the first leader sequence exon of some $V_{H}$ gene ele- ments, amplification with $\mathrm{LSP} / \mathrm{C} \mu$ also would be expected to yield product from some mature $\mathrm{V}_{\mathrm{H}} \mathrm{DJ} \mathrm{J}_{\mathrm{H}} \mathrm{C}$ products. In confirmation of this expected cross-priming, amplification of cDNA from a human B cell hybridoma ODB4, which produces mature VDJC $\mu$, yielded a 650 -bp product. The 360 -bp and 650-bp bands have been cloned in pUC18 and sequenced, confirming that they are $\mathrm{LS}-\mathrm{C} \mu$ and $\mathrm{V}_{\mathrm{H}} \mathrm{DJ}_{\mathrm{H}} \mathrm{C} \mu$, respectively (data not shown).

Normal bone marrow amplification. Amplification of cDNA from normal bone marrow with the LSP/C $\mu$ primers yielded the 360-bp band and a collection of bands migrating between 600 and $700 \mathrm{bp}$ (Fig. 2). These bands were identified from primary amplification by Southern blotting and hybridization with the $\mathrm{p} \mu \mathrm{HM} 2 \mu$ chain cDNA probe and from secondary amplification by ultraviolet light transillumination with ethidium bromide staining. The 360 -bp band from a primary amplification was excised from a gel by comparison to molecular weight markers, reamplified, cloned, and sequenced. Two $5^{\prime}$ terminal sequences were found with near identity to the hybrid cell cDNA clone $\mu \mathrm{b} 9$ (Fig. 3 ). The first sequence, $732-33$, had three nucleotides difference (out of 54) from the LSH6 derived original LS-C $\mu$. The second sequence, 73 5-4, had eight substitutions from the $\mu \mathrm{b} 9$ sequence, with two substitutions in common with 2-33. The ATG initiation of translation codon and open reading frame are conserved in these variants of $\mu \mathrm{b} 9$. The sequence differences from $\mu \mathrm{b} 9$ result in two amino acid substitutions in 2-33, and in three substitutions for 5-4. One and two, respectively, of these substitutions are conservative for polar charge. All of the substitutions retain sequences that are within the variation observed for known heavy chain leader sequences, suggesting that these two additional sequences function as leader sequences for translation of $\mathrm{C} \mu$ into polypeptide.

The observed sequence variation in upstream leader sequences likely represents polymorphism in the LS exon rather than PCR artifact for two reasons. First, the 2-33 sequence has been found on seven additional clones derived from this and from another amplification of the same cDNA, which would

\section{A}

$\mu \mathrm{bg}$

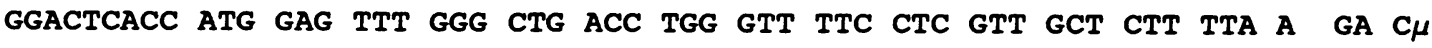

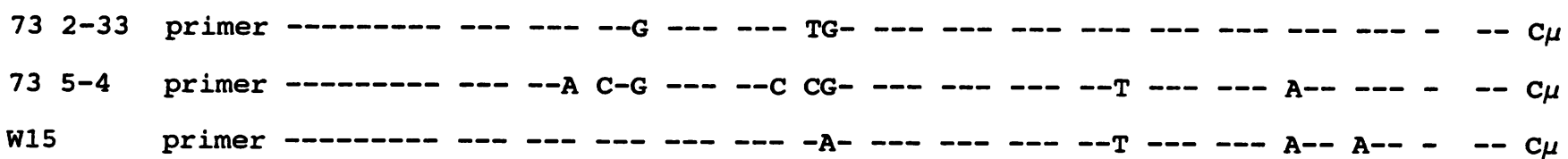

B

mb9 Met Glu Phe Gly Leu Thr Trp Val Phe Leu Val Ala Leu Leu Arg

73 2-33 - - Leu - - Cys - - - - - - -

73 5-4 - - Leu - - Arg - - - - - - - Ile -

W15 - - _ _ - Asn - - _ - - - - Ile Ile

Figure 3. Sequences of LS-C $\mu$ amplification products. $(A)$ cDNA sequences of LSP/CMIII amplified products from normal bone marrow (73 2-33 and 73 5-4) and from XLA bone marrow from one patient (W15). (B) Derived amino acid sequence of the cDNA sequences. The sequence of cDNA clone $\mu \mathrm{b} 9$, an LS-C $\mu$ producing pre-B cell hybrid from normal fetal liver is given in the top line. Bases (DNA) and residues (amino acids) that are identical to $\mu \mathrm{b} 9$ are indicated by a (-) dash. Upstream sequence is derived from the LSP primer used for amplification. 
require the same substitutions to be made early in two separate reactions. The 5-4 sequence was found in two clones from one reaction. It may represent a second allele of LS exon in this individual. Second, no variation has been found in the 246 nucleotides of $\mathrm{C} \mu$ determined from these clones. This suggests that there is a high degree of polymorphism in the LS exons of different individuals. The bands migrating between 600 and $700 \mathrm{bp}$ have not been sequenced, but hybridization of these bands with probes for $C_{\mu}, J_{H}$, and $V_{H} 1$ and $V_{H} 3$ seems sufficient to confirm that they represent mature VDJC $\mu$. The several bands between 600 and 700 bp suggest that the LSP primer hybridizes upstream of multiple $\mathrm{V}_{\mathrm{H}}$ gene elements, and that the variation in size results from the variability in $\mathrm{N}$ region insertion of the $V_{H}$ to $D$ and $D$ to $J_{H}$ joins.

$5^{\prime}$ flanking sequences that would be primed by LSP have been identified from the published sequences of gene elements from the $V_{H} 1,3$, and 4 gene families. Of published $V_{H}$ gene sequences, 27 extend far enough upstream to be able to determine whether the LSP primer would cross-hybridize. Of those $27 V_{H}$ gene elements, 9 have sufficient identity to amplify with the LSP primer in the PCR reaction.

Amplification of cDNA from normal peripheral blood lymphocytes yielded only the 600- to 700-bp bands characteristic of mature VDJC $\mu$ (Fig. 2). Absence of the 360-bp LS-C $\mu$ band from circulating lymphocytes is consistent with the germ line transcription of LS-C $\mu$ from the heavy chain locus in precursor cells resident in bone marrow. Normal fetal liver from a 22-wk abortus amplified with $\mathrm{LSP} / \mathrm{C} \mu$ primers was used as a counterpart to normal bone marrow that would not be enriched for mature $\mathrm{V}_{\mathrm{H}} \mathrm{DJ}_{\mathrm{H}} \mathrm{C} \mu$ sequences from plasma cells. Amplification of the fetal liver cDNA with $\mathrm{LSP} / \mathrm{C} \mu$ primers yielded 360 - and 600- to 700-bp bands that were comparable to those found with normal bone marrow (data not shown).

$X L A$ bone marrow amplification. Amplification of cDNA from bone marrow mononuclear cells of three unrelated XLA patients with $\mathrm{LSP} / \mathrm{C} \mu$ primers yielded only the 360 -bp band (Fig. 4). This band was identified in the primary amplification from two of the patient samples. No amplification product was detected from the primary amplification of the third patient,

Product of XLA Bone Marrow

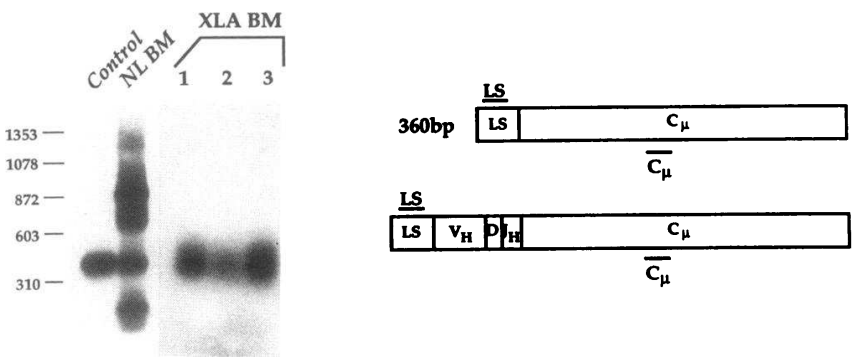

Figure 4. LSP amplification of XLA bone marrow. Autoradiogram of the PCR amplification products of bone marrow cDNA from three XLA patients are shown in comparison to the products from normal bone marrow cDNA. Patient samples 1 and 2 are the products of a single amplification. The sample from patient 3 was put through a second round of amplification. The control lane is amplification of LSH6 cDNA. The positions of the primers and the cDNA amplified are shown schematically. The photograph is a composite from two exposures of a single blot.

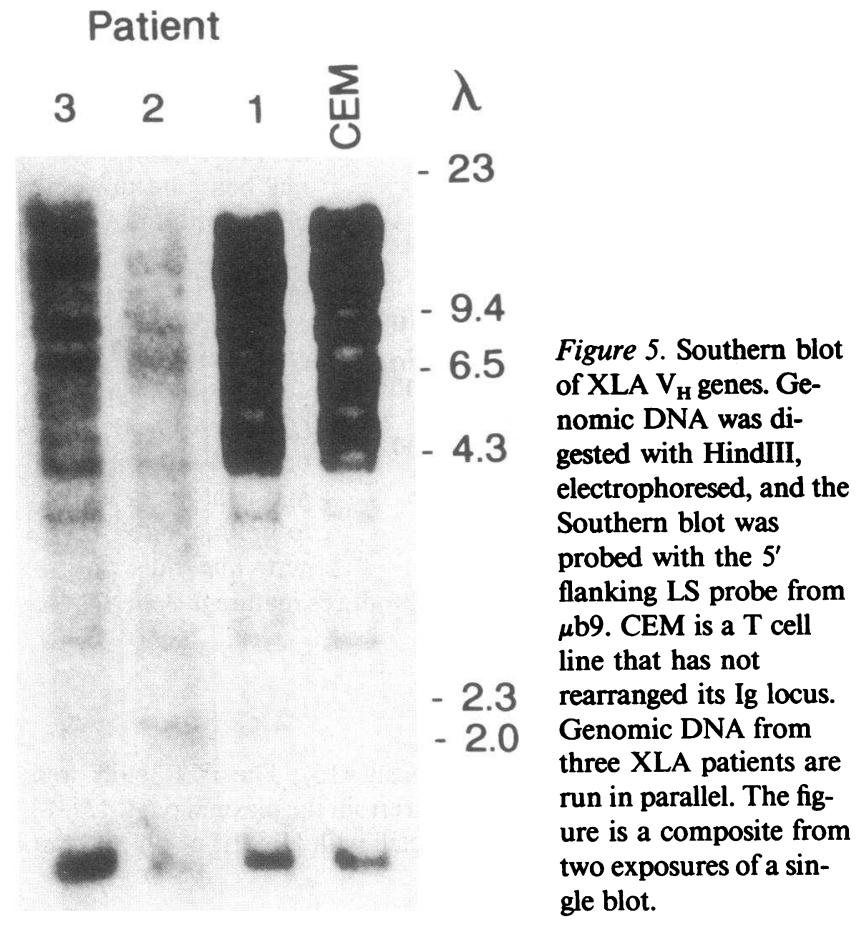

but the 360-bp band was detected after a secondary amplification from this sample. The 600 - to 700 -bp products characteristic of mature VDJC $\mu$ were absent. Production of the 360-bp band serves as an internal control for the amplification reaction. The absence of VDJC $\mu$ amplification products is not due to absence of $V_{H}$ gene elements with LSP first exon. Southern blotting of genomic DNA from two of these patients probed with the $5^{\prime}$ flanking fragment of $\mu \mathrm{b} 9$ revealed the same collection of bands as found from several normal individuals (Fig. 5). Genomic DNA from the third patient was not available. Because of the wide distribution of LSP homology across gene elements from several $V_{H}$ gene families, the absence of bands in the 600 - to 700 -bp range strongly suggests that there is failure of $\mathrm{V}(\mathrm{D}) \mathrm{J}$ recombination in the XLA pre-B cells.

The 360-bp band from one patient was cloned and sequenced (Fig. 3). As with the clones from normal bone marrow, clone $\mathrm{W} 15$ had near identity to the $\mu \mathrm{b} 9$ sequence. Five nucleotide changes were identified in the 54 nucleotides of sequence. This sequence was obtained from five clones from one amplification. Only two of the substitutions were shared with the sequences from normal bone marrow. The nucleotide substitutions were conservative of the ATG initiation codon and of the open reading frame in phase for translation of $\mathrm{C} \mu$ through the putative leader sequence. As with the normal bone marrow clones, no changes were observed in the 246 nucleotides of $\mathrm{C} \mu$ sequence determined, further evidence for polymorphism in the LS exon. Thus, XLA bone marrow pre-B cells produce germ line LS-C $\mu$ transcripts but lack expression of at least a sizeable proportion of mature $\mathrm{VDJC} \mu$ molecules.

The possibility that XLA pre-B cells produce only mature $\mu$ chains that lack homology to $\mu \mathrm{b} 9$ was tested by use of primers specific for conserved sequences in the coding regions from the $\mathrm{V}_{\mathrm{H}} 1,2$, and 3 gene families. $\mathrm{VDJC} \mu$ amplification products were identified in normal bone marrow with the $\mathrm{V}_{\mathrm{H}} 1,2$, and 3 primers (Fig. 6). In contrast, no amplification products were 
A

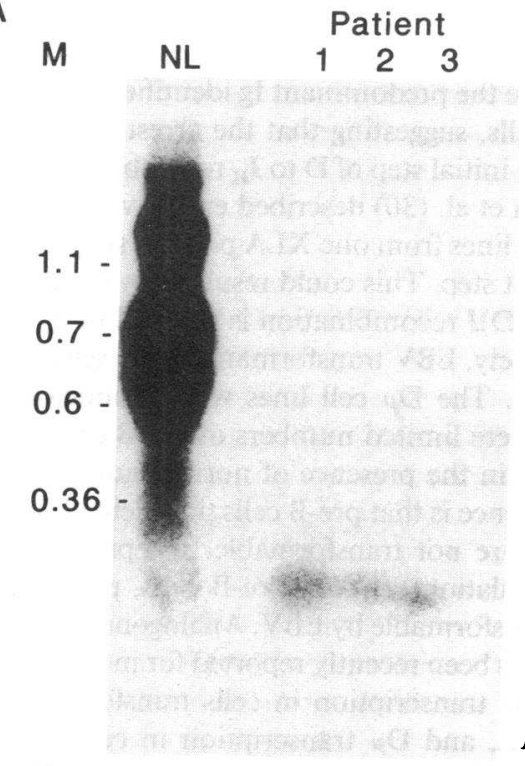

VH 1,2,3 CM III primers
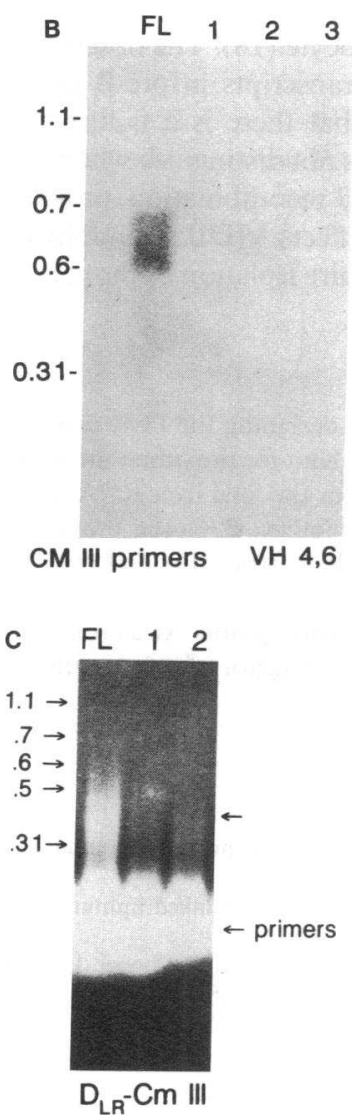

Figure 6. PCR assay for rearranged products. (A) Amplification with primers for $\mathrm{V}_{\mathrm{H}} 1,2,3$ gene families. No amplification products were identified from the three XLA patient samples. The bands near the bottom of the autoradiogram are primers which variably transfer to the membrane. $(B)$ Amplification with primers for $V_{H} 4,6$. An autoradiogram of the primary amplification is shown. Fetal liver cDNA amplification is shown. Similar bands were seen with normal bone marrow. $(C) \mathrm{Am}$ plification with the DLR primer. Bands corresponding in size to D/CMIII amplification products were identified by ultraviolet transillumination from two patient samples (shown), but these bands could not be confirmed by autoradiography. The third patient sample did not yield evidence for $\mathrm{DJ}_{\mathrm{H}} \mathrm{C} \mu$.

identified from the three XLA patients, despite the use of secondary amplifications and hybridization of Southern blots to increase sensitivity. Absence of $\mathrm{V}_{\mathrm{H}} / \mathrm{C} \mu$ amplification from patient bone marrow was found using the three $V_{H}$ primers together and individually in amplifications, and repeated in at least three amplifications for each sample. Normal fetal liver cDNA amplified with these primers yielded 500- to 600-bp bands (data not shown), indicating that mature $\mu$ could be

identified in a population that was composed predominantly of pre-B cells.

To test for biased usage of $V_{H}$ gene elements, primers for the $V_{H^{4}} 4$ and $V_{H} 6$ gene families were used for amplification. These primers amplified mature $\mathrm{V}_{\mathrm{H}}(4,6) \mathrm{DJ}_{\mathrm{H}} \mathrm{C} \mu$ molecules in normal fetal liver (Fig. 6). As with the other $V_{H}$ primers, no amplification products were identified from the XLA bone marrow samples. Normal bone marrow was not tested with these primers.

To test for the products of $\mathrm{DJ}_{\mathrm{H}}$ intermediate recombination, bone marrow cDNA was amplified with primers specific for the DXP, DLR, and DHQ52 gene elements. As shown in Fig. 1, the products of these primers should migrate between 380 and $420 \mathrm{bp}$. Amplification of fetal liver and normal bone marrow yielded a collection of bands in this size range, identified by ethidium staining and by Southern hybridization (Fig. 6). cDNA from two patients yielded bands in the 380 - to 420 bp band by ethidium staining in one experiment (Fig. 6, DLR amplification is shown). These bands hybridized with $C_{\mu}$ and $J_{H}$ probes on Southern blots. cDNA from the third patient yielded no product with any of the $\mathrm{D}$ gene primers. The variable presence of these products suggests that $\mathrm{DJ}_{\mathrm{H}}$ intermediate products are present in low abundance, near the limits of detection by PCR with these primers.

We performed several control experiments to ensure that the absence of $V_{H}$ amplification was not artifactual. Primers internal to $\mathrm{C} \mu$ were used to determine the abundance of $\mu$ chain cDNA in the samples. $\mu$ chain cDNA was somewhat less abundant in XLA bone marrow than in fetal liver, most likely due to the absence of either mature B cells or plasma cells in the XLA samples (data not shown). However, the difference in abundance is not sufficient to explain the absence of any $V_{H}$ amplification from the XLA samples. A 250-bp piece of the housekeeping enzyme PGK was amplified from each of the samples as a control for cDNA quantitation. Two XLA cDNAs examined yielded comparable amounts of the PGK product as fetal liver cDNA, indicating that comparable amounts of cDNA were present. Each sample was amplified on at least three separate occasions with fetal liver or normal bone marrow positive controls as well as negative controls amplified in parallel. Combined with the absence of LSP primed VDJC $\mu$, the absence of $V_{H}$ specific amplification indicates that there is little, if any, VDJC $\mu$ in the bone marrow of these XLA patients.

\section{Discussion}

Examination of bone marrow from three patients with XLA by PCR amplification indicates that the predominant Ig species present is the LS-C $\mu$ germ line transcript. $\mathrm{D} \mu$ transcripts from the $\mathrm{DJ}_{\mathrm{H}}$ intermediate stage of recombination are variably present in limited abundance. Transcripts of mature $\mathrm{V}_{\mathrm{H}} \mathrm{DJ} \mathrm{J}_{\mathrm{H}} \mathrm{C} \mu$ recombination are lacking, both as molecules primed by the LSP 5 ' flanking leader sequence primer and by $V_{H}$ coding sequence primers from five of the six human $V_{H}$ gene families. These results are in agreement with previous studies by somatic cell hybridization (18), indicating that the absence of mature $\mathrm{V}_{\mathrm{H}} \mathrm{DJ}_{\mathrm{H}} \mathrm{C} \mu$ molecules in XLA pre-B cell hybrids is representative of the Ig species present in pre-B cells in XLA bone marrow. I conclude that $\mathrm{V}(\mathrm{D}) \mathrm{J}$ recombination is a rate-limiting step in XLA pre-B cells, and suggest that the failure of pre-B cell development characteristic of this disease may result from failure of $\mathrm{V}(\mathrm{D}) \mathrm{J}$ recombination. 
I found a complete absence of mature $\mu$ chains priming with the LSP primer. By sequence homology, this primer would amplify fully one-third of published $V_{H}$ gene elements, including genes from three $V_{H}$ families. PCR amplification of normal bone marrow, fetal liver, and peripheral blood and Southern blotting of genomic DNA confirms the high abundance of sequence homology with the LSP primer. These amplifications have the internal control of amplified LS-C $\mu$ germ line transcripts. Amplification with $\mathrm{V}_{\mathrm{H}}$ coding sequence primers also indicates the absence of $\mathrm{VDJC} \mu$ molecules. Studies of $V_{H}$ gene utilization have shown preferential utilization of the most $3^{\prime} V_{H}$ gene elements early in fetal life $(21,22)$. Primers for $V_{H^{4}} 4$ and $V_{H} 6$, representing the most $3^{\prime}$ human $V_{H}$ gene elements, showed that the absence of $\mathrm{V}_{\mathrm{H}} \mathrm{DJ}_{\mathrm{H}} \mathrm{C} \mu$ does not result from mimicry of early fetal development. The amplifications with $\mathrm{V}_{\mathrm{H}}$ coding primers lack the internal control of LSP amplification. Various controls were used to compensate for this, and the ready amplification of normal tissues compared to consistent absence of amplification of XLA bone marrow in parallel experiments performed several times argues strongly against technical artifact as the basis for absence of VDJC $\mu$ amplification products.

The arrest in B cell development of XLA patients is not absolute. Rare B lymphocytes have been identified in peripheral blood of some patients (4), and B cell lines have been established from these cells by Epstein-Barr virus transformation $(23,24)$. Ig heavy and light chains of these cell lines have fully productive, normal $V(D) J$ recombinations, indicating normal recombinase activity. Transfection studies and the effects of the murine severe combined immunodeficiency mutation suggest that $B$ and $T$ cells share a single recombinase for creation of their antigen receptors $(11,25)$. $T$ cell-mediated immunity is normal in XLA (1), further indicating that the recombinase is not affected. It seems most likely that a normal recombinase acts in both $\mathrm{T}$ and $\mathrm{B}$ cells of XLA, but the rate of recombination is greatly reduced in $B$ cells. Leakiness resulting in a limited amount of $\mathrm{V}(\mathrm{D}) \mathrm{J}$ recombination is consistent with observations in other genetic diseases. Thalassemia resulting from mutation in an RNA splice site is associated with production of some normal globin (see reference 26 , for example), and severe combined immunodeficiency in mice resulting from aberrant recombinase activity is associated with some normal $\mathrm{V}(\mathrm{D}) \mathrm{J}$ recombination (27).

Mature $\mu$ chains of the rare XLA B lymphocytes were not detected by PCR amplification. This may result from rapid entry of any cell that does create a productive VDJ into peripheral circulation. Conley (4) identified B lymphocytes in peripheral blood of XLA patients at a frequency between 1:100 and 1:1,000 of normal. A previous study of XLA bone marrow examined sufficient numbers of cells to have identified B cells at this frequency, but did not identify any (3). There is variability between patients in the degree of leakiness in generating $B$ cells. We do not know the degree of leakiness in the patients we studied. However, reconstruction experiments of PCR amplifications with the primers we used indicate that we could detect mature $\mu$ chain with as little as $0.1 \mathrm{ng}$ of normal fetal liver cDNA, corresponding to a 1,000 -fold reduction in numbers of $B$ cells in XLA bone marrow compared to normal.

The recombinase is proposed to be directed in its sequential steps by regulation of access (10). Access for recombination is closely associated with transcriptional activation of the recombining gene elements $(13,14)$. LS-C $\mu$ germ line transcripts pre- cede $\mathrm{D}$ to $\mathrm{J}_{\mathrm{H}}$ recombination (15); $\mathrm{D} \mu$ and unrearranged $\mathrm{V}_{\mathrm{H}}$ transcripts precede $V_{H}$ to $D_{H}$ recombination $(28,29)$. LS-C $\mu$ germ line transcripts are the predominant Ig identified in XLA bone marrow pre-B cells, suggesting that the arrest in $\mathrm{V}(\mathrm{D}) \mathrm{J}$ recombination is at the initial step of $D$ to $J_{H}$ recombination in these patients. Ichihara et al. (30) described exclusive production of $\mathrm{D} \mu$ in pre-B cell lines from one XLA patient, suggesting arrest at the subsequent step. This could result from variation in the step at which V(D)J recombination is arrested in different patients. Alternatively, EBV transformation may select for more mature $\mathrm{D} \mu$ cells. The $\mathrm{D} \mu$ cell lines were monoclonal, suggesting that there were limited numbers of pre-B cells that could be transformed, in the presence of normal numbers of pre-B cells. Our experience is that pre-B cells producing LS-C $\mu$ germ line transcripts are not transformable by Epstein-Barr virus. The major population of XLA pre-B cells, producing LS-C $\mu$, may not be transformable by EBV. Analogous differential transformability has been recently reported for murine preB cells, with germ line transcription in cells transformed by Harvey leukemia virus, and $D \mu$ transcription in cells transformed by Abelson leukemia virus (14).

We have proposed that XLA results from a primary defect in Ig V(D)J recombination as a primary cause for arrest in the transition from pre-B cell to B lymphocyte (18). The observed predominance of $\mathrm{LS}-\mathrm{C} \mu$ germ line transcripts in pre-B cells from three XLA patients confirms that there is a failure of $\mathrm{V}(\mathrm{D}) \mathrm{J}$ recombination. This result does not distinguish whether the XLA gene directly regulates $V(D) J$ recombination, or acts in regulation of a gene that directly affects $V(D) J$ recombination. Resolution of this issue may require isolation of the gene.

\section{Acknowledgments}

I gratefully acknowledge the assistance in designing the PCR experiments provided by Alan Beggs. I thank B. Kim for providing the normal bone marrow sample, Eric Hoffman for the fetal liver RNA, and Stuart Orkin for education in molecular biology. F. Rosen provided valuable discussion. In memory of Sam Latt, who provided critical intellectual support for this research.

Supported by National Institutes of Health grants AI 21163 and 21165. J. Schwaber was an Established Investigator of the American Heart Association.

\section{References}

1. Rosen, F., M. Cooper, and R. Wedgwood. 1984. The primary immunodeficiencies. N. Engl. J. Med. 311:235-242.

2. Schwaber, J., and F. Rosen. 1990. X chromosome linked immunodeficiency. Immunodefic. Rev. 2:233-251.

3. Pearl, E., L. Vogler, A. Okos, W. Crist, A. Lawton, and M. Cooper. 1978. B lymphocyte precursors in human bone marrow: analysis of normal individuals and patients with antibody-deficiency states. J. Immunol. 120:1169-1175.

4. Conley, M. E. 1985. B cells in patients with X-linked agammaglobulinemia. J. Immunol. 134:3070-3074.

5. Fearon, E., J. Winkelstein, C. Civin, D. Pardoll, and B. Vogelstein. 1987 Carrier detection in $\mathrm{X}$-linked agammaglobulinemia by analysis of $\mathrm{X}$ chromosome inactivation. N. Engl. J. Med. 316:427-431.

6. Conley, M., and J. Puck. 1988. Carrier detection in typical and atypical X-linked agammaglobulinemia. J. Pediatr. 112:688-694.

7. Honjo, T. 1983. Immunoglobulin genes. Annu. Rev. Immunol. 1:499-528.

8. Early, P., H. Huang, M. Davis, K. Calame, and L. Hood. 1980. An immunoglobulin heavy chain variable region gene is generated from three segments of DNA, $\mathrm{V}_{\mathrm{H}}, \mathrm{D}$, and $\mathrm{J}_{\mathrm{H}}$. Cell. 19:981-992.

9. Sakano, H., Y. Kurosawa, M. Weigert, and S. Tonegawa. 1981. Identification and nucleotide sequence of a diversity DNA segment (D) of immunoglobulin heavy chain genes. Nature (Lond.). 290:562-565.

10. Alt, F., G. Yancopoulos, T. Blackwell, C. Wood, E. Thomas, M. Boss, R. Coffman, N. Rosenberg, S. Tonegawa, and D. Baltimore. 1984. Ordered rear- 
rangement of immunoglobulin heavy chain variable region segments. $E M B O$ (Eur. Mol. Biol. Organ.) J. 3:1209-1219.

11. Yancopoulos, G., T. K. Blackwell, and F. Alt. 1986. Introduced T cel receptor variable region gene segments recombine in pre-B cells: evidence that $B$ and $T$ cells use a common recombinase. Cell. 44:251-259.

12. Alt, F., T. K. Blackwell, R. dePinho, M. Reth, and G. Yancopoulos. 1986. Regulation of genome rearrangement events during lymphocyte differentiation. Immunol. Rev. 89:5-30.

13. Blackwell, T. K., M. Moore, G. Yancopoulos, H. Suh, S. Lutzker, E. Selsing, and F. Alt. 1986. Recombination between immunoglobulin variable region gene segments is enhanced by transcription. Nature (Lond.). 324:585-589.

14. Schlissel, M., L. Corcoran, and D. Baltimore. 1991. Virus-transformed pre-B cells show ordered activation but not inactivation of immunoglobulin gene rearrangement and transcription. J. Exp. Med. 173:711-720.

15. Schwaber, J., and B. Malone. Germ line transcription of the Ig heavy chain locus directs production of $\mu$ chain without VDJ. J. Clin. Invest. 89:20462052.

16. Schlissel, M., and D. Baltimore. 1989. Activation of immunoglobulin kappa gene rearrangement correlates with induction of germline kappa gene transcription. Cell. 58:1001-1007.

17. Siu, G., M. Kronenberg, E. Strauss, R. Haars, T. Mak, and L. Hood. 1984 The structure, rearrangement and expression of $\mathrm{D} \beta$ gene segments of the murine $T$ cell antigen receptor. Nature (Lond.). 311:344-350.

18. Schwaber, J., H. Molgaard, S. Orkin, H. Gould, and F. Rosen. 1983. Pre-B cells from normal and X-linked agammaglobulinemic individuals produce $\mu$ chains without associated variable regions. Nature (Lond.). 304:355-358.

19. Chirgwin, J., A. Przybyla, R. MacDonald, and R. Rutter. 1979. Isolation of biologically active ribonucleic acid from sources enriched in ribonuclease. Biochemistry. 18:5294-5300.

20. Ravetch, J., U. Siebenlist, S. Korsmeyer, T. Waldmann, and P. Leder. 1981. Structure of human immunoglobulin $\mu$ locus: characterization of embryonic and rearranged $\mathrm{J}$ and $\mathrm{D}$ genes. Cell. 27:583-591.
21. Yancopoulos, G., S. Desiderio, M. Paskind, J. Kearney, D. Baltimore, and F. Alt. 1984. Preferential utilization of the most $J_{H}$ proximal $V_{H}$ gene segments in pre-B cell lines. Nature (Lond.). 311:727-733.

22. Schroeder, H., J. Hillson, and R. Perlmutter. 1987. Early restriction of the human antibody repertoire. Science (Wash. DC). 238:791-793.

23. Mensink, E., R. Schuurman, J. Schot, A. Thompson, and F. Alt. 1986. Immunoglobulin heavy chain gene rearrangements in X-linked agammaglobulinemia. Eur. J. Immunol. 16:963-967.

24. Anker, R., M. Conley, and B. Pollok. 1989. Clonal diversity in the B cell repertoire of patients with X-linked agammaglobulinemia. J. Exp. Med. 169:2109-2119.

25. Schuler, W., I. Weller, A. Schuler, R. Phillips, T. Mak, J. Kearney, R. Perry, and M. Bosma. 1986. Rearrangement of antigen receptor genes is defective in mice with severe combined immune deficiency. Cell. 46:963-972.

26. Treisman, R., S. Orkin, and T. Maniatis. 1983. Structural and functional defects in beta thalassemia. Prog. Clin. Biol. Res. 134:99-121.

27. Bosma, G., M. Fried, R. Custer, A. Carroll, D. Gibson, and M. Bosma 1988. Evidence of functional lymphocytes in some (leaky) scid mice. J. Exp. Med. 167:1016-1033.

28. Reth, M., and F. Alt. 1984. Novel immunoglobulin heavy chains are produced from $\mathrm{DJ}_{\mathrm{H}}$ gene segment rearrangements in lymphoid cells. Nature (Lond.). 312:418-423.

29. Yancopoulos, G., and F. Alt. 1985. Developmentally controlled and tissue-specific expression of unrearranged $\mathrm{V}_{\mathrm{H}}$ gene segments. Cell. 40:271-281.

30. Ichihara, Y., H. Matsuoka, I. Tsuge, J. Okada, S. Torii, H. Yasui, and Y. Kurosawa. 1988. Abnormalities in DNA rearrangements of immunoglobulin gene loci in precursor $\mathrm{B}$ cells derived from $\mathrm{X}$-linked agammaglobulinemia patient and a severe combined immunodeficiency patient. Immunogenetics. 27:330337.

31. Hoch, S., and J. Schwaber. 1987. Identification and sequence of the $V_{H}$ gene elements encoding an anti-DNA antibody. J. Immunol. 139:1689-1693. 